\title{
Video Article \\ Mechanism of Regulation of Adipocyte Numbers in Adult Organisms Through Differentiation and Apoptosis Homeostasis
}

\author{
Aline Bozec ${ }^{1,2}$, Nicole Hannemann ${ }^{1,2}$ \\ ${ }^{1}$ Department of Medicine 3, Rheumatology and Immunology, Universitätsklinikum Erlangen \\ ${ }^{2}$ Nikolaus Fiebiger Center of Molecular Medicine, Universitätsklinikum Erlangen
}

Correspondence to: Aline Bozec at aline.bozec@uk-erlangen.de

URL: https://www.jove.com/video/53822

DOI: doi:10.3791/53822

Keywords: Developmental Biology, Issue 112, Adipocytes, adipocytes differentiation, adipocyte dysregulation, adipose tissue, hypoxia, HIF1a, metabolic syndrome, obesity, aging

Date Published: 6/3/2016

Citation: Bozec, A., Hannemann, N. Mechanism of Regulation of Adipocyte Numbers in Adult Organisms Through Differentiation and Apoptosis Homeostasis. J. Vis. Exp. (112), e53822, doi:10.3791/53822 (2016).

\section{Abstract}

Considering that adipose tissue (AT) is an endocrine organ, it can influence whole body metabolism. Excessive energy storage leads to the dysregulation of adipocytes, which in turn induces abnormal secretion of adipokines, triggering metabolic syndromes such as obesity, dyslipidemia, hyperglycemia, hyperinsulinemia, insulin resistance and type 2 diabetes. Therefore, investigating the molecular mechanisms behind adipocyte dysregulation could help to develop novel therapeutic strategies. Our protocol describes methods for evaluating the molecular mechanism affected by hypoxic conditions of the AT, which correlates with adipocyte apoptosis in adult mice. This protocol describes how to analyze AT in vivo through gene expression profiling as well as histological analysis of adipocyte differentiation, proliferation and apoptosis during hypoxia exposure, ascertained through staining of hypoxic cells or HIF-1a protein. Furthermore, in vitro analysis of adipocyte differentiation and its responses to various stimuli completes the characterization of the molecular pathways behind possible adipocyte dysfunction leading to metabolic syndromes.

\section{Video Link}

The video component of this article can be found at https://www.jove.com/video/53822/

Introduction

According to the 2014 report from the World Health Organization, $39 \%$ of the world's adult population is overweight, and $13 \%$ is obese ${ }^{1}$. In the near future, overweight people will comprise a significant proportion of the elderly population. An important feature of obesity and aging is dysregulation of fat in relation to morbidity and mortality ${ }^{2}$. Adipokines, proteins secreted by the adipose tissue (AT), can trigger metabolic syndromes such as obesity and type 2 diabetes ${ }^{3}$. Metabolic diseases are mostly caused by excessive energy storage in the lipid droplets of adipocytes, which results in AT expansion ${ }^{4}$. It is therefore of interest to determine the causes and the molecular mechanisms of AT expansion in order to find opportunities to control it.

Over-nutrition leads to AT expansion, which is regulated by two events: excessive energy storage into the lipid droplets of adipocytes, a process leading to hypertrophy (increase in adipocyte size), and increased adipogenesis, also known as adipocyte hyperplasia ${ }^{5}$. Adipogenesis is a process of differentiation of multipotent mesenchymal stem cells (MSC) into adipocytes. Firstly, MSCs develop into preadipocytes during the commitment phase. Secondly, preadipocytes further differentiate to acquire the features of mature and functional adipocytes ${ }^{6}$. Several transcription factors have been identified as master regulators for preadipocyte determination, such as zinc finger protein 423 (Zfp423) and early B cell factor 1 (Ebf1). Whereas Zfp423 induces early commitment, Ebf1 is required for the generation of adipocyte progenitors ${ }^{6}$. Terminal differentiation is tightly controlled by a transcriptional cascade, whereby peroxisome proliferator-activated receptor Y (PPARY) is the essential transcription factor ${ }^{7}$. Further key transcriptional factors are the CCAAT/enhancer-binding protein (C/EBP) family members (i.e., C/EBPa, C/ $\mathrm{EBP} \beta$, and C/EBPD), kruppel-like factors (KLFs), cAMP responsive element binding protein (CREB) and early growth response 20 (Krox20) ${ }^{6}$.

Recently, it has been shown that the activator protein-1 (AP-1) family is involved in the adipocyte differentiation process ${ }^{8,9}$. The AP-1 family is formed by a dimeric protein complex, composed of Fos, Jun and/or activating transcription factor (ATF) members. Fos-related antigen 1 and 2 (Fra-1 and Fra-2) are able to regulate adipocyte differentiation. Fra-1 impairs adipocyte differentiation by inhibiting C/EBPa ${ }^{8}$, whereas Fra-2 controls adipocyte turnover ${ }^{9}$. Fra-2 thereby not only decreases the adipocyte number by repressing PPARY2 expression during adipocyte differentiation, but also decreases adipocyte apoptosis through direct repression of hypoxia-inducible factors (HIFs) expression. The HIF family is a heterodimeric transcription factor complex, composed of HIF-1 $\alpha, \mathrm{HIF}-2 \alpha$ and HIF-1 $\beta$. The heterodimers consist of an oxygen-sensitive HIF$\alpha$ protein (HIF-1 $\alpha$ or HIF-2 $\alpha$ ) and the oxygen-insensitive HIF-1 $\beta$ subunit ${ }^{10}$. During normoxia, HIF- $\alpha$ proteins are poly-ubiquitinylated and are finally degraded by proteasomes ${ }^{11}$. Under hypoxic conditions, occurring in AT during expansion, HIF- $\alpha$ proteins are no longer hydroxylated. They therefore become stabilized and form dimers with the constitutively expressed HIF-1 $\beta$. Transcriptional activation of genes controlled by the HIF response elements is involved in the regulation of angiogenesis, metabolism, and inflammation ${ }^{12}$. Indeed, HIF-1 $\alpha$ promotes AT dysfunction 
by inducing glucose tolerance, inhibiting energy expenditure and peripheral use of lipid, as well as by increasing leptin level and HFD-induced hepatic steatosis ${ }^{13}$. Moreover, HIF-1 $\alpha$ regulates adipocyte apoptosis in vivo and in vitro ${ }^{9}$

The present protocol describes methods for studying AT status to unravel the molecular characteristics of adipocyte homeostasis in adult mice. It shows how apoptosis, proliferation and differentiation of adipocytes in vivo and in vitro can be regulated by hypoxia. To do so, we use mice with adipocyte specific deletion of Fra-2 generated by crossing mice carrying the Fra-2 floxed alleles with Fabp4-CreERT mice ${ }^{9}$. By using Fabp4-Cre ERT mice, the deletion is adipocyte specific and inducible by tamoxifen injection ${ }^{14}$. For the adult model, intra peritoneal injections of tamoxifen are performed over 5 consecutive days starting at the age of 6 weeks. Thus, the mice are subjected to a normal diet or high-fat diet for 6 weeks before the analysis is done. The mice used in this study were male based on a C57BI6 background to avoid female hormones, such as estrogens, shown to regulate the body fat distribution ${ }^{15}$. Using another genetic background might also alter the metabolic phenotype, due to strain-related differences in lipid management ${ }^{16}$.

This protocol demonstrates how to analyze AT under hypoxia using histology and how to quantify adipocyte apoptosis, proliferation and differentiation in vivo using immunohistochemistry and gene profiling analyses. The study is completed by in vitro experiments, showing how to analyze primary adipocyte differentiation and apoptosis altered by exposure to hypoxia.

\section{Protocol}

ETHICS STATEMENT: Animals are housed in standardized conditions following the guidelines of the German Animal Welfare Act. Animals are fed a standard diet and water ad libitum and kept with a $12 \mathrm{hr}$ day/night cycle. All experiments with animals are authorized by the local ethics committee.

\section{In Vivo Analysis of Adipocyte Homeostasis in Adult Males}

1. To quantify hypoxia in vivo, first determine the body weight of the mice, then inject $60 \mathrm{mg} / \mathrm{kg}$ body weight of solid pimonidazole hydrochloride intra-peritoneally (for example: inject $1.5 \mathrm{mg}$ into a $25 \mathrm{~g}$ mouse). Pimonidazole is an effective hypoxic marker, which forms adducts with thiol groups in proteins, peptides and amino acids and is detected by a specific antibody.

2. Sacrifice mice and remove the perigonadal fat pads (Figure 1).

1. $45 \mathrm{~min}$ after injection, sacrifice mice by $\mathrm{CO}_{2}$ asphyxiation and subsequent cervical dislocation.

2. Pin down the limbs of mice (as illustrated in Figure 1) and open the peritoneal cavity. Remove the left and the right perigonadal (epididymal) fat pad inside the peritoneal cavity.

Note: Fat pad are bound to the epididymis by the peritoneal leaflets as shown in Figure 1 (perigonadal fat pads are indicated by arrows).

3. Take care to remove the gonadal tissues from the fat pad. Determine fat pad weights to calculate the ratio: fat pad weight ( $\mathrm{g}$ ) per body weight $(\mathrm{g})$.

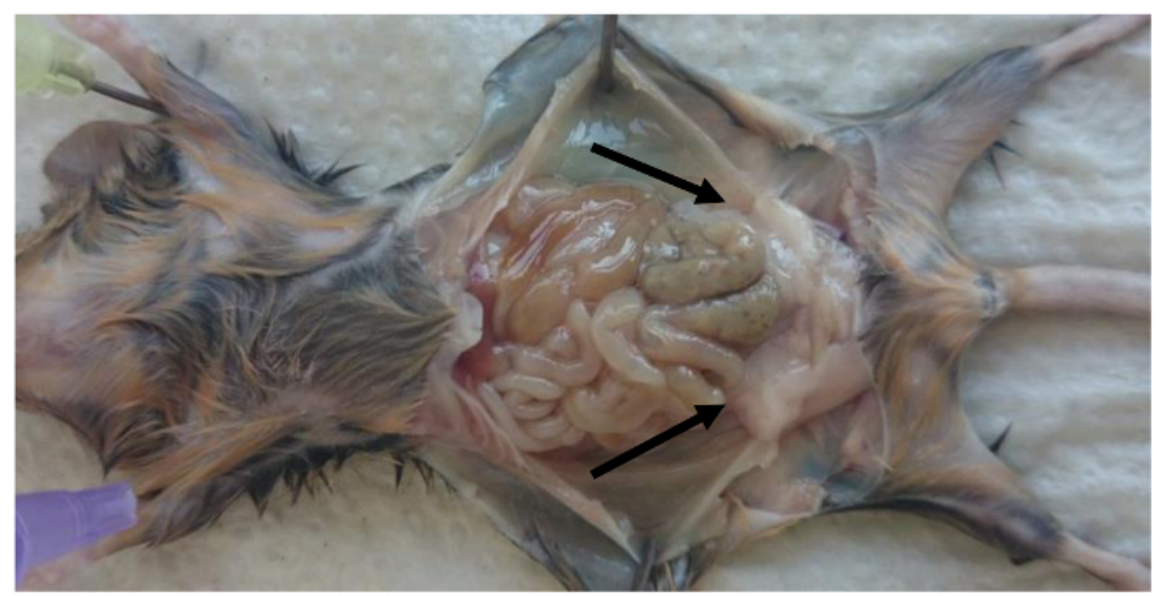

Figure 1: Location of the perigonadal fat pads in the peritoneal cavity of mice. Picture of perigonadal fat localization in adult mice after sacrifice. Perigonadal fat pads are indicated by the arrows. Please click here to view a larger version of this figure.

3. To compile a quantitative gene expression profile, use one perigonadal fat pad to isolate RNA. Note: Until the tissue is processed, store tissue samples in RNA stabilization solution at $-80^{\circ} \mathrm{C}$ or in liquid nitrogen.

1. To homogenize the fat pad, add the fat pad to $1 \mathrm{ml}$ single-phase solution of guanidine isothiocyanate and phenol. Use tubes containing ceramic beads $(1.4 \mathrm{~mm}$ ) to crush the tissue in a homogenizer at 6,500 rpm (2 times $20 \mathrm{sec}$, with $30 \mathrm{sec}$ pause).

2. Isolate the RNA as follows (single-step method by Chomczynski and Sacchi ${ }^{17}$ ).

1. To separate the phases, transfer homogenized fat pad to microcentrifuge tube, add $0.2 \mathrm{ml}$ volume chloroform, shake for $15 \mathrm{sec}$ incubate for $5 \mathrm{~min}$ at room temperature and centrifuge $12,000 \mathrm{xg}$ for $5 \mathrm{~min}$. Transfer the upper aqueous phase (around $400 \mu \mathrm{l}$ ), which contains the RNA, into a new microcentrifuge tube. Do not include the DNA-containing interphase or the protein-containing phenol phase. 
2. To precipitate the RNA, add 1 volume of isopropanol, mix and incubate for $15 \mathrm{~min}$ at $4{ }^{\circ} \mathrm{C}$ (it is also possible to incubate at -20 ${ }^{\circ} \mathrm{C}$ overnight). Centrifuge at $12,000 \mathrm{xg}$ for $10 \mathrm{~min}$. Remove isopropanol supernatant carefully. Wash twice with $75 \%$ ethanol with centrifuge steps of $12,000 \times \mathrm{g}$ for $10 \mathrm{~min}$.

3. After drying the precipitated RNA for around $10 \mathrm{~min}$ at room temperature, dissolve it in $50 \mu \mathrm{l} \mathrm{H}_{2} \mathrm{O}$ (RNase-free). To facilitate this, incubate for 2 min at $65^{\circ} \mathrm{C}$.

Note: Keep RNA in $75 \%$ ethanol at $-80^{\circ} \mathrm{C}$ or in liquid nitrogen for long-term storage.

4. Quantify the RNA preparations by $A_{260 / 280}$ (optimal quotient is between 1.8 and 2.2) and calculate the concentration by $A_{260}$ : conc $[\mu \mathrm{g} / \mathrm{ml}]=O D_{260} * 40[\mu \mathrm{g} / \mathrm{ml}] *$ dilutionfactor

3. To avoid DNA contamination, digest $1 \mu \mathrm{g}$ of the RNA preparation with $1 \mathrm{U}$ DNase I for $30 \mathrm{~min}$ at $37^{\circ} \mathrm{C}$ in a volume of $10 \mu \mathrm{I}$. Inactivate at $65^{\circ} \mathrm{C}$ for $10 \mathrm{~min}$.

Note: This step is optional.

4. Use $10 \mu \mathrm{l}$ of RNA preparation containing $1 \mu \mathrm{g}$ RNA for the reverse transcriptase reaction to generate single-stranded cDNA, suitable for quantitative PCR application. The components and their amounts are listed in Table 1.

5. Use a PCR Master Mix for a quantitative real-time PCR reaction. To determine metabolic changes in the whole fat pad, use specific primers for genes involved in AT homeostasis (Table 2) and the PCR conditions listed in Table 3.

6. Real-time PCR data analysis.

1. Define the baseline (Figure 2), normally cycle 1 to 15 , where there is no change in fluorescence signals. The real-time PCR software normalizes specific fluorescence signals to the baseline fluorescence and to the internal reference dye, ROX, resulting in the magnitude of the specific signals by the primers, delta $R n(\Delta R n)$.

2. Set the threshold within the exponential phase of the amplification curve. The intersection defines the threshold cycle (Ct). Based on the CT value, calculate the relative expression $(\Delta \mathrm{Ct})$ and the fold change $(\Delta \Delta \mathrm{Ct})$ :

$$
\begin{aligned}
& \Delta C t=\frac{2^{C t(\text { housekesping })}}{2^{\text {Ct(target })}} \\
& \Delta \Delta C t=\frac{\Delta C t(\text { treatment })}{\Delta C t(\text { control })}
\end{aligned}
$$

\begin{tabular}{|l|l|}
\hline Component & Volume $\mu \mathrm{l} /$ reaction \\
\hline $10 x$ RT Buffer & 2.0 \\
\hline $25 x$ dNTP Mix $(100 \mathrm{mM})$ & 0.8 \\
\hline $10 x$ RT Random Primers & 2.0 \\
\hline MultiScribe Reverse Transcriptase & 1.0 \\
\hline Nuclease-free $\mathrm{H}_{2} \mathrm{O}$ & 4.2 \\
\hline $1 \mu \mathrm{g}$ RNA & 10 \\
\hline Total per reaction & 20 \\
\hline
\end{tabular}

Table 1: Components with respective volume for the reverse transcriptase reaction to generate single-stranded cDNA. 


\begin{tabular}{|c|c|c|c|c|}
\hline & \multirow[t]{2}{*}{ Official full name } & \multirow[t]{2}{*}{ Symbol } & \multicolumn{2}{|l|}{ Sequence $3^{\prime}-->5^{\prime}$} \\
\hline & & & Forward & Reverse \\
\hline \multirow[t]{11}{*}{ Adipogenesis } & $\begin{array}{l}\text { Delta-like } 1 \text { homolog } \\
\text { (pref-1) }\end{array}$ & Dlk1 & $\begin{array}{l}\text { GACACTCGAAGCTCA } \\
\text { CCTGG }\end{array}$ & $\begin{array}{l}\text { GGAAGGCTGGGACGG } \\
\text { GAAAT }\end{array}$ \\
\hline & Early B cell factor 1 & Ebf1 & $\begin{array}{l}\text { CCACCATCGACTACGG } \\
\text { CTTC }\end{array}$ & $\begin{array}{l}\text { TCCTGGTTGTTGTGGGG } \\
\text { CATC }\end{array}$ \\
\hline & Zinc finger protein 423 & Zfp423 & $\begin{array}{l}\text { GTGCCCAGGAAGAAGA } \\
\text { CGTA }\end{array}$ & $\begin{array}{l}\text { GGCGACGTGGATCTGA } \\
\text { ATCT }\end{array}$ \\
\hline & $\begin{array}{l}\text { Fatty acid binding protein } 4 \\
\text { (Ap2) }\end{array}$ & Fabp4 & $\begin{array}{l}\text { TCACCTGGAAGACAGCT } \\
\text { CCTC }\end{array}$ & $\begin{array}{l}\text { AAGCCCACTCCСACTTC } \\
\text { TTTC }\end{array}$ \\
\hline & $\begin{array}{l}\text { CCAAT/enhancer binding } \\
\text { protein (C/EBP), alpha }\end{array}$ & Cebpa & $\begin{array}{l}\text { AAGAGCCGCGACA } \\
\text { AGGC }\end{array}$ & $\begin{array}{l}\text { GTCAGCTCCAGCACCT } \\
\text { TGTG }\end{array}$ \\
\hline & $\begin{array}{l}\text { CCAAT/enhancer binding } \\
\text { protein (C/EBP), beta }\end{array}$ & Cebpb & $\begin{array}{l}\text { TTTCGGGACTTGATGC } \\
\text { AATC }\end{array}$ & $\begin{array}{l}\text { CCGCAGGAACATCTTT } \\
\text { AAGG }\end{array}$ \\
\hline & $\begin{array}{l}\text { cAMP responsive element } \\
\text { binding protein } 1\end{array}$ & Creb1 & $\begin{array}{l}\text { ACTCAGCCGGGTACT } \\
\text { ACCAT }\end{array}$ & $\begin{array}{l}\text { TTGCTGCCTCCCTGTT } \\
\text { CTTC }\end{array}$ \\
\hline & $\begin{array}{l}\text { CCAAT/enhancer binding } \\
\text { protein (C/EBP), delta }\end{array}$ & Cebpd & $\begin{array}{l}\text { CAGCGCCTACATTGAC } \\
\text { TCCA }\end{array}$ & $\begin{array}{l}\text { GTTGAAGAGGTCGGCG } \\
\text { AAGA }\end{array}$ \\
\hline & Kruppel-like factor 4 & KIf4 & $\begin{array}{l}\text { GCAGTCACAAGTCCCC } \\
\text { TCTC }\end{array}$ & $\begin{array}{l}\text { TAGTCACAAGTGTGGG } \\
\text { TGGC }\end{array}$ \\
\hline & $\begin{array}{l}\text { Early growth response } 2 \\
\text { (Krox20) }\end{array}$ & Egr2 & $\begin{array}{l}\text { AGGCGGTAGACAAAATC } \\
\text { CCAG }\end{array}$ & $\begin{array}{l}\text { GATACGGGAGATCCAG } \\
\text { GGGT }\end{array}$ \\
\hline & $\begin{array}{l}\text { Peroxisome proliferator } \\
\text { activated receptor gamma }\end{array}$ & Pparg & $\begin{array}{l}\text { AGAGGTCCACAGAGCTG } \\
\text { ATTC }\end{array}$ & $\begin{array}{l}\text { GATGCACTGCCTATGAGC } \\
\text { ACTT }\end{array}$ \\
\hline \multirow[t]{3}{*}{ Lipogenesis } & $\begin{array}{l}\text { Acetyl-Coenzyme A } \\
\text { carboxylase alpha }\end{array}$ & Acaca & $\begin{array}{l}\text { TGGGGACCTTGTCTTCA } \\
\text { TCAT }\end{array}$ & $\begin{array}{l}\text { ATGGGCGGAATGGTCTC } \\
\text { TTTC }\end{array}$ \\
\hline & Fatty acid synthase & Fasn & $\begin{array}{l}\text { ACATCCTAGGCATCC } \\
\text { GAGA }\end{array}$ & $\begin{array}{l}\text { CCGAGTTGAGCTGGGT } \\
\text { TAGG }\end{array}$ \\
\hline & $\begin{array}{l}\text { Stearoyl-Coenzyme A } \\
\text { desaturase } 1\end{array}$ & Scd1 & $\begin{array}{l}\text { CGGGATTGAATGTTCTTG } \\
\text { TCGT }\end{array}$ & $\begin{array}{l}\text { TTCTTGCGATACACTCTG } \\
\text { GTGC }\end{array}$ \\
\hline Lipolysis & $\begin{array}{l}\text { Patatin-like phospholipase } \\
\text { domain containing } 2\end{array}$ & Pnpla2 & $\begin{array}{l}\text { AAGGACCTGATGACCA } \\
\text { CCCT }\end{array}$ & $\begin{array}{l}\text { CCAACAAGCGGATGGT } \\
\text { GAAG }\end{array}$ \\
\hline \multirow[t]{2}{*}{ Fatty acid uptake } & Lipoprotein lipase & Lpl & $\begin{array}{l}\text { GTATCGGGCCCAGCAA } \\
\text { CATTATCC }\end{array}$ & $\begin{array}{l}\text { GCCTTGCTGGGGTTTTC } \\
\text { TTCATTC }\end{array}$ \\
\hline & CD36 antigen & Cd36 & $\begin{array}{l}\text { GTCTTCCCAATAAGCATGT } \\
\text { CTCC }\end{array}$ & $\begin{array}{l}\text { ATGGGCTGTGATCGGA } \\
\text { ACTG }\end{array}$ \\
\hline \multirow[t]{4}{*}{ Hypoxia } & $\begin{array}{l}\text { Hypoxia inducible factor } 1 \text {, } \\
\text { alpha subunit }\end{array}$ & Hif1a & $\begin{array}{l}\text { CCTGCACTGAATCAAGAG } \\
\text { GTGC }\end{array}$ & $\begin{array}{l}\text { CCATCAGAAGGACTTGCT } \\
\text { GGCT }\end{array}$ \\
\hline & $\begin{array}{l}\text { Endothelial PAS domain } \\
\text { protein } 1 \text { (also known as: } \\
\text { HIF-2alpha) }\end{array}$ & Epas1 & $\begin{array}{l}\text { CAAGCTGAAGCTAAAG } \\
\text { CGGC }\end{array}$ & $\begin{array}{l}\text { TTGGGTGAATTCATCG } \\
\text { GGGG }\end{array}$ \\
\hline & $\begin{array}{l}\text { Von Hippel-Lindau tumor } \\
\text { suppressor }\end{array}$ & Vhl & $\begin{array}{l}\text { ACCGAGGTCATCTTTG } \\
\text { GCTC }\end{array}$ & $\begin{array}{l}\text { TTCCGCACACTTGGGT } \\
\text { AGTC }\end{array}$ \\
\hline & $\begin{array}{l}\text { Aryl hydrocarbon receptor } \\
\text { nuclear translocator (also } \\
\text { known as: HIF-1beta) }\end{array}$ & Arnt & $\begin{array}{l}\text { TGGGTCATCTTCTCGC } \\
\text { GGTT }\end{array}$ & $\begin{array}{l}\text { TGTCCTATCTGAGCAT } \\
\text { CGTG }\end{array}$ \\
\hline
\end{tabular}

Table 2: List of genes with sequence of the respective primers used for analyzing adipocyte homeostasis. 


\begin{tabular}{|l|l|l|l|l|}
\hline Step & & Temperature $\left({ }^{\circ} \mathrm{C}\right)$ & Time $(\mathrm{min}: \mathrm{sec})$ \\
\hline Polymerase activation & \multirow{2}{*}{$\begin{array}{l}\text { PCR } \\
\text { PCycles }\end{array}$} & Hold & 95 & $10: 00$ \\
\hline Melting curve & & Denaturize & 95 & $0: 15$ \\
\cline { 3 - 5 } & & Annealing/Extension & 60 & $1: 00$ \\
\hline
\end{tabular}

Table 3: Real-time PCR conditions.

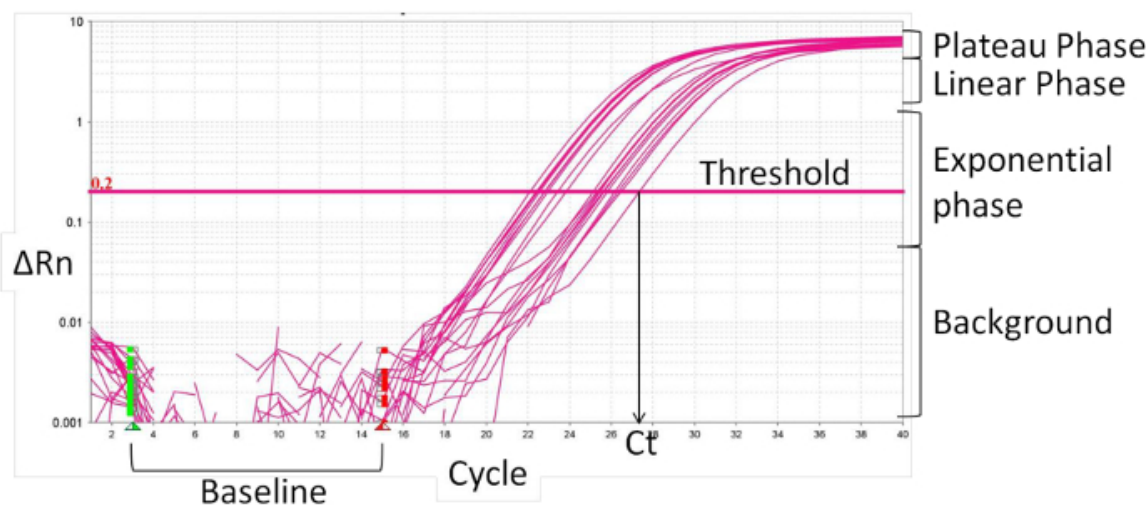

Figure 2: Characteristics of real-time PCR amplification curve. Please click here to view a larger version of this figure.

4. To perform histological analysis of the adipocyte homeostasis, use the second perigonadal fat pad. Do not desiccate the tissue!

1. Fix the fat pad in $3.7 \%$ PBS-buffered formaldehyde overnight, embed in paraffin (follow the instructions as described elsewhere ${ }^{18}$ ) and cut the embedded tissue into $2-5 \mu \mathrm{m}$ thick sections (maximum $5 \mu \mathrm{m}$ ).

2. Determine the number of adipocytes per field and adipocyte size in a bright-field microscope after hematoxylin and eosin (H\&E) staining:

1. Deparaffinize sections by washing 3 times for $5 \mathrm{~min}$ in xylene and rehydrate the section 2 times for 2 min in $100 \%$ ethanol and 2 times for 2 min in $96 \%$ ethanol. Finally, wash the section in distilled $\mathrm{H}_{2} \mathrm{O}$ for 5 min.

2. Stain with hematoxylin, diluted $1: 5$ with distilled $\mathrm{H}_{2} \mathrm{O}$, for 10 min at room temperature and wash in $\mathrm{H}_{2} \mathrm{O}$ for 5 min. Stain with eosin solution ( $20 \mathrm{ml} 5 \%$ eosin Y/210 ml distilled $\mathrm{H}_{2} \mathrm{O} / 25 \mu$ l glacial acetic acid) for 30 sec and wash again with $\mathrm{H}_{2} \mathrm{O}$ for $5 \mathrm{~min}$.

3. Dehydrate sections using $96 \%$ ethanol and $100 \%$ ethanol 2 times each for 2 min, and xylene 3 times for 5 min. Mount the sections with anhydrous mounting agent.

4. Evaluate the sections under a bright-field microscope. A representative example of how to analyze adipocytes with Image $1.48 \mathrm{v}$ ${ }^{19}$ is shown in Fig. 3: number of cells per area $\left(\mu \mathrm{m}^{2}\right)$, cell area $\left(\times 10^{3} \mu \mathrm{m}^{2}\right)$, cell size $(\mu \mathrm{m})$.

1. Open the picture of the section with ImageJ $1.48 \mathrm{v}$. If the parameters of the image are indicated in pixels instead of a unit of length, adjust the scale.

2. Select *Straight line* in the toolbar and adjust the line to a known distance by reference to the scale bar. Go to Analyze -> Set Scale. The distance of the line is shown in pixels; add the known distance and the unit of length, e.g., $\mu \mathrm{m}$. Confirm with $O K$. The size of the picture and the analysis of the parameters are indicated in the unit of length given.

3. To determine the parameters of the adipocytes, adjust the threshold. Go to Image -> Adjust $\rightarrow>$ Threshold to open the Threshold window. Select the following settings: Thresholding method: Default; Threshold color: B\&W; Color space: HSB. The picture is now shown in black and white. Adjust the Brightness to clear white adipocytes and to close black intercellular spaces, as in Fig. $\mathbf{3 b}$.

4. Count the number of adipocyte per $\mu \mathrm{m}^{2}$ (Figure $3 \mathbf{e}$ ) with the ${ }^{*}$ multi-point ${ }^{*}$ selection in the toolbar and mark each cell for counting.

5. To determine the adipocyte size, select *Straight line* again in the toolbar and draw the diameter of an adipocyte (Figure 3c). Go to Analyze -> Measure and a new window will appear, with the length of the diameter in $\mu \mathrm{m}$.

6. To determine the adipocyte area, select *Wand (tracing) tool* and click inside the adipocyte. The inner wall of the adipocyte is selected in red (Figure 3d). Go to Analyze -> Measure and a new window will appear, with the area of this adipocyte in $\mu \mathrm{m}^{2}$.

3. For immunohistochemistry, prepare the section for antibody and TdT-mediated dUTP-biotin nick end labeling (TUNEL) staining as follows:

1. Deparaffinize sections by washing 3 times for $5 \mathrm{~min}$ in xylene and rehydrate the section 2 times for 2 min in $100 \%$ ethanol and 2 times for 2 min in $96 \%$ ethanol. Finally, wash the section in distilled $\mathrm{H}_{2} \mathrm{O}$.

2. For antigen retrieval, digest the tissue section for $30 \mathrm{~min}$ at $37^{\circ} \mathrm{C}$ with Proteinase $\mathrm{K}$ working solution $(20 \mu \mathrm{g} / \mathrm{ml}$ in $10 \mathrm{mM}$ Tris/ $\mathrm{HCl}, \mathrm{pH}$ 7.4-8) and rinse with PBS.

4. Perform antibody staining in wet chambers:

1. To block the endogenous peroxidase, use $3 \%$ hydrogen peroxide in PBS for $10 \mathrm{~min}$, with subsequently washing 2 times for 5 min in PBS. To block the unspecific binding of antibodies, use $10 \%$ serum in PBS. Use the serum of the host of the secondary antibody, in this case goat. 
2. For the staining, use the antibodies for apoptosis, proliferation and hypoxia detection (Table 4). Dilute antibodies in PBS/10\% goat serum. Incubate at $4{ }^{\circ} \mathrm{C}$ overnight. Wash the sections 3 times for 5 min in PBS.

3. To enhance the signal use a biotinylated secondary antibody, with the dilution as listed in Table 5. For hypoxia detection, use HRP conjugated rabbit anti-FITC as the secondary antibody. Incubate for $1 \mathrm{hr}$ at room temperature. Wash the sections 2 times 5 min with PBS.

Note: For the hypoxia staining with FITC-MAb1, skip step 1.4.4.4) and continue with step 1.4.4.5).

4. For each slide, pre-incubate $50 \mu \mathrm{l}$ avidin solution with $50 \mu \mathrm{l}$ biotinylated peroxidase $\mathrm{H}$ for $30 \mathrm{~min}$ at room temperature (this method is also referred to as avidin/biotin $A B C$ complex formulation) and then add to the sections for another 45 min. Wash 2 times for 5 min with PBS.

5. Incubate the sections in peroxidase substrate solution until the staining become more intense (between 5 to $10 \mathrm{~min}$ ). Wash for 5 min with distilled $\mathrm{H}_{2} \mathrm{O}$.

6. For counterstaining, stain with hematoxylin diluted $1: 5$ with distilled $\mathrm{H}_{2} \mathrm{O}$ for 10 min at room temperature and wash in $\mathrm{H}_{2} \mathrm{O}$ for 5 $\min$.

7. Dehydrate sections in $96 \%$ ethanol and $100 \%$ ethanol 2 times each for $2 \mathrm{~min}$, and xylene 3 times for 5 min. Seal the sections with coverslips and anhydrous mounting agent. Evaluate the sections under a bright-field microscope.

5. Determine apoptosis by TUNEL assay and follow manufacturer's instructions:

1. Add $50 \mu \mathrm{l}$ enzyme solution into $450 \mu$ label solution. Then apply $50 \mu \mathrm{l}$ TUNEL reaction mixture on histologic sections and incubate for $60 \mathrm{~min}$ at $+37^{\circ} \mathrm{C}$ in a humidified atmosphere in the dark. Wash the sections 3 times with PBS for 5 min and mount with fluorescence mounting medium including DAPI (4',6-diamidino-2-phenylindole) for counterstaining.

2. Evaluate the section under a fluorescence microscope with 100 fold magnification. For measurement of Fluorescein use an excitation wavelength of $488 \mathrm{~nm}$ and detect between 515-565 nm (green laser); DAPI excites at about $360 \mathrm{~nm}$ and emits at about $460 \mathrm{~nm}$ when bound to DNA (blue laser).

3. Quantify the overlays of DAPI and Fluorescein:

$\%$ apoptotic adipocytes $=\left(\frac{\text { number of positive apoptotic nuclei }}{\text { number of adipocytes }}\right) * 100$

(a)

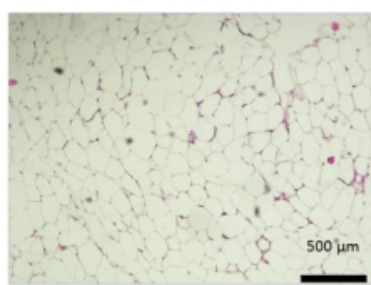

(b)

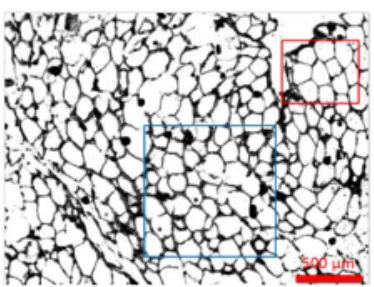

(c)

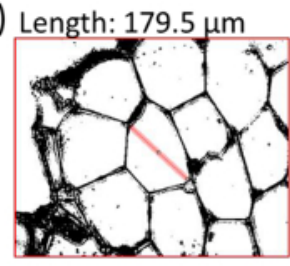

(e)

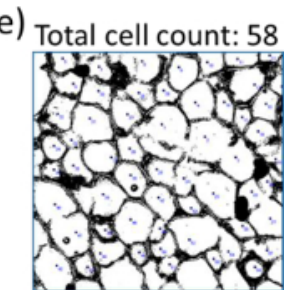

(d) Area: $20.2\left(\times 10^{3} \mu \mathrm{m}^{2}\right)$

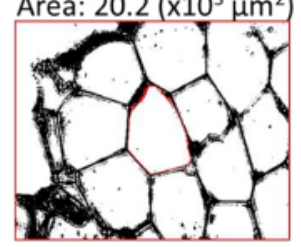

Figure 3: Analyzing adipocyte characteristics in fat pad sections. Section pictures of the perigonadal fat pad of male mice treated with a high-fat diet (HFD) or normal diet (ND) with a bright-field microscope (a); the threshold is adjusted into black and white (b) and the adipocyte size (length; $\mathbf{c})$, area (d) and adipocyte cell number per $\mathrm{mm}^{2}(\mathbf{e})$ are quantified with ImageJ $1.48 \mathrm{v}$. Please click here to view a larger version of this figure.

\begin{tabular}{|l|l|l|}
\hline & Stock concentration & dilution \\
\hline Apoptosis & $\begin{array}{l}\text { Cleaved Caspase-3 (Asp175) (5A1E) Rabbit } \\
\text { mAb }\end{array}$ & $1: 2,000$ \\
\hline Proliferation & $\begin{array}{l}\text { Purified Mouse Anti-Human Ki-67 Clone } \\
\text { B56 (RUO) }\end{array}$ & $1: 50$ \\
\hline \multirow{2}{*}{ Hypoxia } & HIF-1 alpha Antibody & $1: 100$ \\
\cline { 2 - 3 } & FlTC-MAb1 & $1: 100$ \\
\hline
\end{tabular}

Table 4: Antibodies with respective dilution used for the immunohistological staining of AT sections. 


\begin{tabular}{|l|l|}
\hline Antibody & dilution \\
\hline biotinylated anti mouse $\operatorname{lgG}(\mathrm{H}+\mathrm{L})$ & $1: 200$ \\
\hline biotinylated anti mouse $\operatorname{lgG}(\mathrm{H}+\mathrm{L})$ & $1: 200$ \\
\hline HRP conjugates rabbit anti-FITC & $1: 100$ \\
\hline
\end{tabular}

Table 5: Secondary antibodies with dilution used for immunohistological staining.

\section{In Vitro Analysis of Adipocyte Homeostasis Influenced by Hypoxia}

1. Sacrifice mice and remove the subcutaneous adipose tissue.

1. Sacrifice the mice by $\mathrm{CO}_{2}$ asphyxiation and subsequent cervical dislocation.

2. Pin down the limbs of mice as illustrated in Figure 4. Detach the skin from the upper leg, loin and flank and pin it down with needles as in Figure 4. Then remove the subcutaneous adipose tissue, which is located posterior at the base of the hind legs, surrounding the inguinal lymph nodes (as shown in Figure 4, left: subcutaneous fat pads indicated by the arrows; right: inguinal lymph node indicated by the arrow).

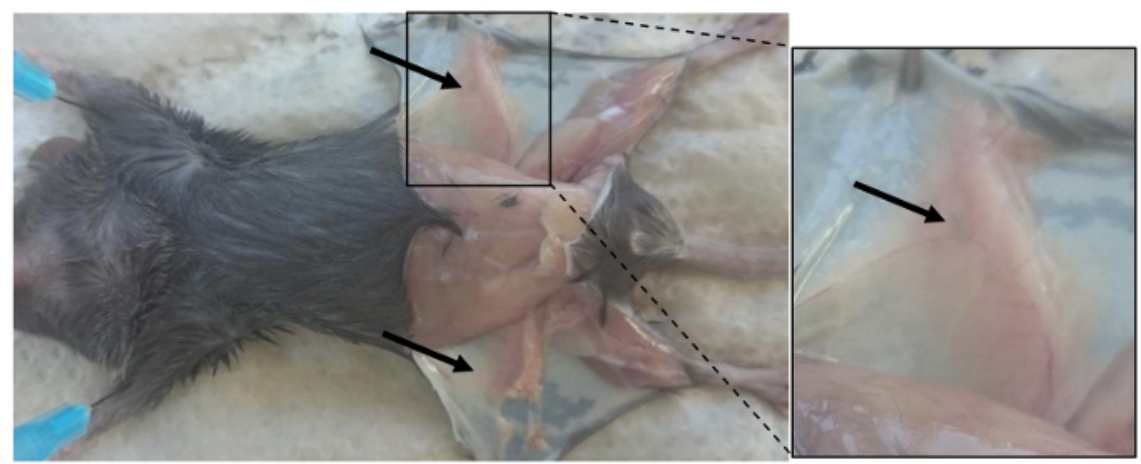

Figure 4: Location of the subcutaneous fat pads. Picture of subcutaneous fat pad; the left arrows indicate the subcutaneous fat pad and the right arrow indicates the inguinal lymph node. Please click here to view a larger version of this figure.

2. Isolate adipose-derived stem cells (ADSC) as previously described ${ }^{20}$.

3. Seed ADSC 4,000 cells $/ \mathrm{cm}^{2}$ in Dulbecco's modified Eagle's medium-Ham's F-12 supplemented with $10 \%$ normal calf serum, $1 \%$ penicillin/ streptomycin, $0.5 \%$ amphotericin $\mathrm{B}, 16 \mu \mathrm{M}$ biotin, $18 \mu \mathrm{M}$ pantothenic acid and $100 \mu \mathrm{M}$ ascorbic acid and grow culture to confluence around 70 to $80 \%$, which is reached after 4 to 6 days of culture.

4. Induce Adipogenic Differentiation.

1. Remove the adherent ADSC from the surface by trypsin treatment.

1. Remove medium, wash with PBS and add $0.025 \%$ trypsin solution (preheated to $37^{\circ} \mathrm{C}$ ) for 2 min (until cells detach from the surface). Immediately add medium and wash the cells.

2. Count the cells using a Neubauer chamber.

1. Put the glass cover on the central area of the Neubauer chamber. Dilute the cell suspension 1:10 and load the chamber with 10 $\mu \mathrm{l}$ diluted cell suspension. Count the cells in 4 squares located at the corners, each composed of 16 smaller squares. Calculate the cell number per ml:

$$
\frac{\text { cells }}{m l}=\left(\frac{\text { cell number }}{4}\right) * 10 * 10,000
$$

3. Seed ADSC (as described in point 2.2) in 12-well culture plates and grow culture to confluence around 70 to $80 \%$ (reached after 4 to 6 days).

4. Induce adipogenic differentiation by adding $5 \mu \mathrm{g} / \mathrm{ml}$ insulin, $1 \mu \mathrm{M}$ dexamethasone and $5 \mu \mathrm{M}$ 3-isobutyl-1-methylxanthine (IBMX) to the cultures. Renew the medium every 2 days. Cells will be fully differentiated after 7 days.

5. To analyze the adipogenic differentiation, stain with Oil Red O, which stains triglycerides of mature adipocytes.

Note: Work must be performed under a fume hood!

1. Remove the medium, wash the adipocytes gently with PBS and fix the cells for 60 min with $2 \mathrm{ml} 10 \%$ formalin.

2. To prepare Oil Red O staining solution, mix 3 parts of the Red Oil O stock solution ( $300 \mathrm{mg}$ Red Oil O powder dissolved in $100 \mathrm{ml} 99 \%$ isopropanol) with 2 parts distilled $\mathrm{H}_{2} \mathrm{O}$ and incubate for $10 \mathrm{~min}$ at room temperature. Filter the Oil Red $\mathrm{O}$ working solution through a 0.2 $\mu \mathrm{m}$ injection filter.

Note: The working solution is stable for $2 \mathrm{hr}$.

3. For the Oil Red O staining, remove the formalin, wash adipocytes with $\mathrm{H}_{2} \mathrm{O}$, incubate with $2 \mathrm{ml} 60 \%$ isopropanol for 5 min, remove the isopropanol and add $2 \mathrm{ml}$ Oil Red $\mathrm{O}$ working solution for $5 \mathrm{~min}$. Rinse the cells with tap water until the water is clear. Counterstain with hematoxylin as in point 1.4.4.5). 
4. Evaluate the plates under a phase contrast microscope with 100 fold magnification. The lipids of the adipocytes will appear red and the nuclei will appear blue.

6. Optional step: Silence the gene of interest by transfection with shRNA.

1. Change the medium and add serum-free medium.

2. For the transfection of adipocytes, use lipofection. Follow the manufacturer's instructions and use $1 \mu \mathrm{g}$ shRNA per 12-well tissue plates. After addition of the lipid-DNA-complex, incubate adipocytes for $48 \mathrm{hr}$ at $37^{\circ} \mathrm{C}$.

7. To analyze adipocytes subjected to hypoxia, use a hypoxic work station or hypoxic incubator to maintain the cells under hypoxic conditions. Depending of the study, hypoxia could be $0.5,1$ or $2 \%$ oxygen.

1. Analyze apoptosis by FITC-labeled Annexin $V$ and subsequent flow cytometry analyses.

1. Gather adipocytes with an extra soft cell scraper, wash with PBS and add $1 \times 10^{6}$ cells to $100 \mu$ Annexin V-binding buffer (10 mM Hepes/NaOH, pH 7.4; $140 \mathrm{mM} \mathrm{NaCl} ; 2.5 \mathrm{mM} \mathrm{CaCl}_{2}$ ). Add the amount of Annexin V-FITC recommended by the manufacturer and incubate at room temperature for $15 \mathrm{~min}$.

2. For flow cytometry measurement, add $200 \mu$ Annexin V-binding buffer and $1 \mu \mathrm{M}$ of nuclear counterstain. Determine the fluorescence in the green and violet channel. Annexin $\mathrm{V}^{+}$/nuclear counterstain ${ }^{+}$cells are defined as secondary necrotic and Annexin $\mathrm{V}^{+}$/nuclear counterstain ${ }^{-}$cells are defined as apoptotic cells (Figure 5).

2. Quantitatively analyze adipocyte RNA level to determine the homeostasis under hypoxic conditions.

1. Add $1 \mathrm{ml}$ single-phase solution of guanidine isothiocyanate and phenol to each well and isolate the RNA [using single-step method by Chomczynski and Sacchi ${ }^{17}$ (step 1.3.2)] and proceed as in steps 1.3.2.1) to 1.3.5.2).

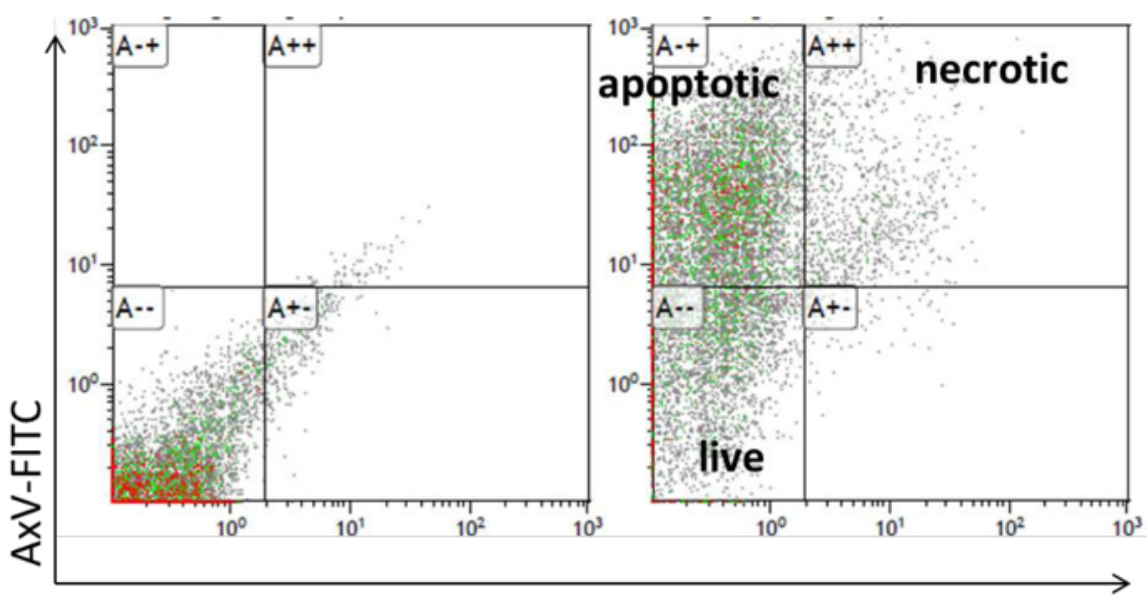

\section{Nuclear counterstain}

Figure 5: Adipocyte apoptosis analysis by flow cytometry. Dot plot presentations of the FACS for Annexin V-FITC and TO-PRO-3 staining of adipocytes. Please click here to view a larger version of this figure.

\section{Representative Results}

We show how to determine adipocyte homeostasis in vivo and in vitro using the example of Fra- $2^{\text {fl/fl }}$ Fabp4-CreERT mice compared to wild-type littermates. Our protocol defines how increased HIF expression by hypoxia is correlated with adipocyte dysfunction as indicated by increased adipocyte apoptosis.

Increased adipocyte size and area in high-fat diet (HFD) treated mice

Over-nutrition, among other factors, results in adipocyte hypertrophy, caused by excessive energy storage in the lipid droplets. The adipocyte size and area is an indicator of hypertrophy. Sections of the fat pad from normal (ND; Figure 6a) and high-fat diet (HFD; Figure 6b) mice as well as quantifications of the adipocyte size and area clearly show adipocyte hypertrophy after 6 weeks of HFD, which is indicated by increased adipocyte size in the HFD treated mice (Figure $6 \mathbf{c}$ and $\mathbf{d}$ ).

Increased hypoxia in the adipose tissue (AT) of adult Fra- ${ }^{\mathrm{f} / \mathrm{fl} l}$ Fabp4-CreERT mice leads to increased HIF-1 $\alpha$ level and adipocyte apoptosis

To determine the in vivo status of hypoxia in AT, Fra- $2^{\text {fl/fl }}$ Fabp4-CreERT mice are analyzed 6 weeks after Fra-2 deletion at the age of 12 weeks and compared with wild-type littermates. Pimonidazole is administered to the mice intraperitoneally as an effective hypoxia marker; it is nontoxic and able to distribute into the AT. Hypoxic adipocytes in the AT in vivo are defined by immunohistochemical antibody staining (Figure 7a). Furthermore, the increased hypoxic status of the AT in mice is accompanied by increased HIF-1a positive adipocytes as indicated by the immunohistochemical staining Figure $7 \mathbf{b}$ ), which is confirmed by quantification of HIF-1a expression levels and its targets genes ${ }^{9}$. Additionally, TUNEL staining of AT sections from Fra- $2^{\text {fl/fl }}$ Fabp4-CreERT mice and control littermates (Figure 7c) shows that increased adipocyte apoptosis is correlated with the presence of hypoxia and HIF-1 $\alpha$ expression. 
Increased HIF-1 $\alpha$ expression in primary adipocytes through hypoxia induced adipocyte apoptosis

To analyze adipocyte apoptosis in vitro, we use adipocytes generated from subcutaneous fat pads as described elsewhere ${ }^{20}$. As expected, the HIF-1 $\alpha$ expression in adipocytes is increased after $24 \mathrm{hr}$ of hypoxia (Figure 8a). To further analyze HIF-1 $\alpha$ activities, the RNA levels of HIF target genes such as Inos (inducible nitric oxide synthase) are quantified by qPCR. Figure $\mathbf{8 b}$ shows that the increased expression of HIF-1 $\alpha$ under hypoxic conditions leads to increased Inos mRNA level. Since we have already shown in vivo (Figure 8) that increased HIF-1a expression in adipocytes correlates with increased adipocyte apoptosis, apoptosis is also quantified in in vitro cultures by Annexin $V$ staining under hypoxic conditions. Consistent with the in vivo data (Figure 7), an increased HIF-1a level is accompanied by increased adipocyte apoptosis induced by hypoxic conditions (Figure 8b). Moreover, to prove that hypoxic-induced apoptosis is HIF-dependent; HIF-1 $\alpha$ or HIF-2 $\alpha$ is silenced by RNA interference in adipocytes derived from wild-type or Fra-2 deficient mice. The increased adipocyte apoptosis is restored by silencing HIF-1 $\alpha$ or HIF-2 $\alpha$ as shown by Annexin V staining in Figure 8b, proving that the hypoxia sensor HIF- $\alpha$ regulates the adipocyte apoptosis.

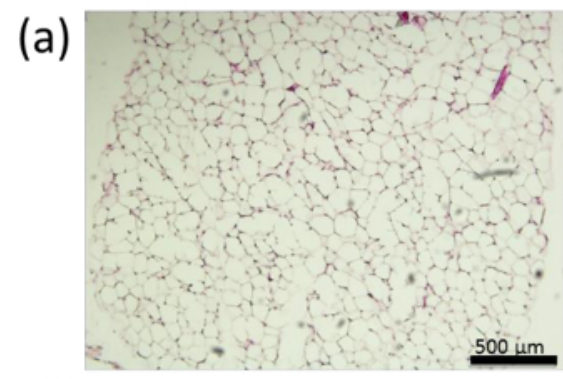

(c)

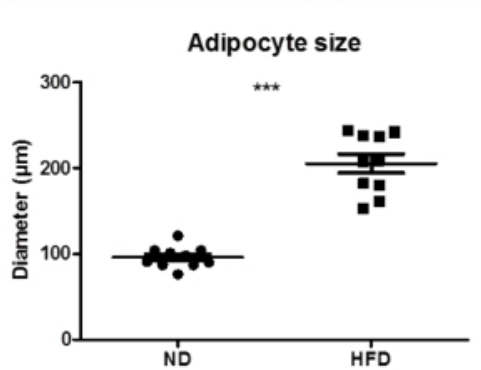

(b)

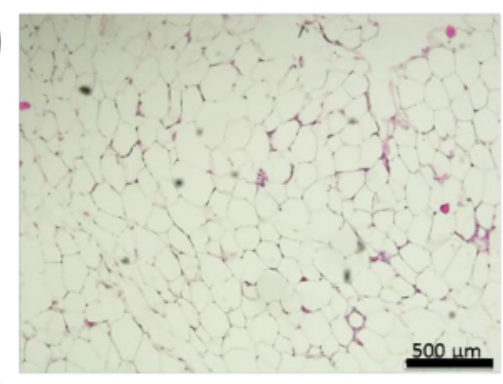

(d)

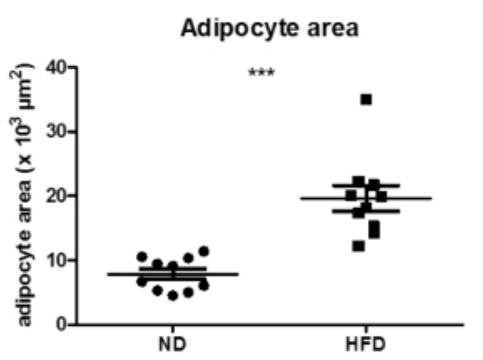

Figure 6: Increased adipocyte size and area in high-fat diet (HFD) mice. (a, b) H\&E staining of sections from the perigonadal fat pad of male wild-type mice fed with normal diet (ND) (a) or high-fat diet (HFD) (b) for 6 weeks. Bars represent $500 \mu \mathrm{m}$. (c, d) Quantifications of adipocyte size (c) and area (d) from the perigonadal fat pad of wild-type mice fed with ND (a) or HFD (b) for 6 weeks. $n=10$. Data are shown as mean values \pm SEM. Statistical analysis was performed using Student's $t$-test. ${ }^{* *} p<0.0001$.Please click here to view a larger version of this figure. 
(a)

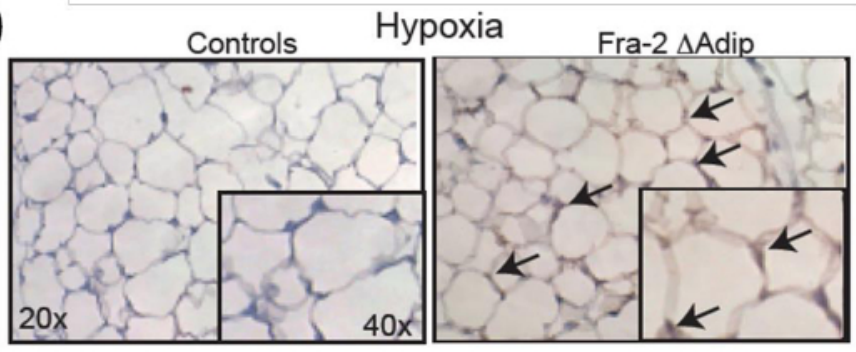

(b)

HIF1 $\alpha \quad$ Fra-2 $\Delta$ Adip

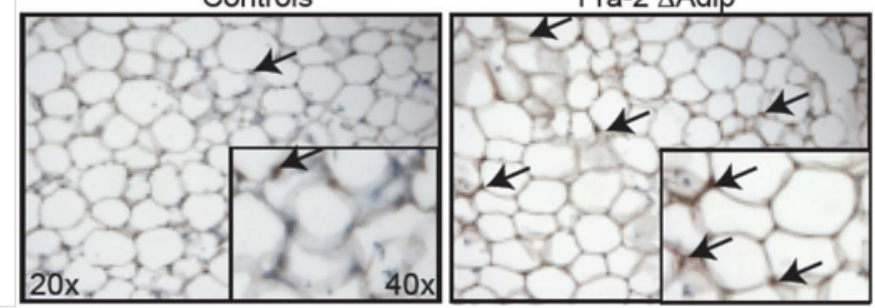

(c)

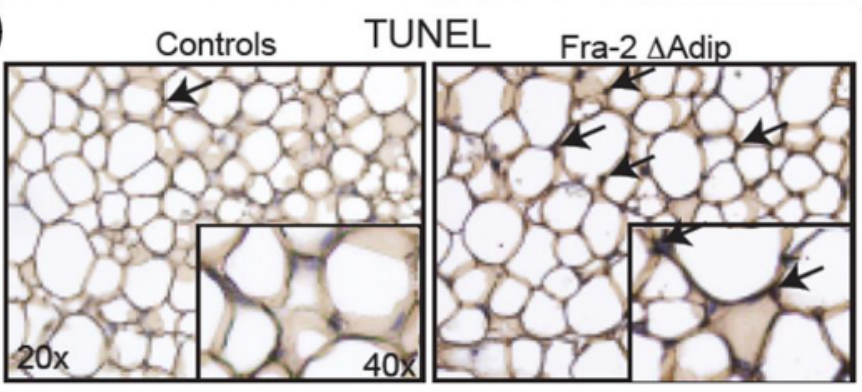

Figure 7: Increased HIF-1a level and apoptosis in adipocytes of adult Fra-2 ${ }^{\mathrm{fl} / \mathrm{fl}}$ Fabp4-CreERT mice. Hypoxia (a) and HIF-1a (b) staining in the AT of male Fra- $2^{\mathrm{fl} / \mathrm{fl}}$ Fabp4-creERT mice and male control littermates 6 weeks after tamoxifen injection. Magnification 20X, insert 40X. Black arrows indicate hypoxic areas and HIF-1a positive cells. (c) TUNEL staining in Fra-2 ${ }^{\mathrm{fl} / \mathrm{fl}}$ Fabp4-CreERT mice and control littermates AT 6 weeks after tamoxifen injection. Magnification 20X, insert 40X. Black arrows indicate TUNEL positive cells. This figure has been modified from Luther et al. ${ }^{9}$. Please click here to view a larger version of this figure. 


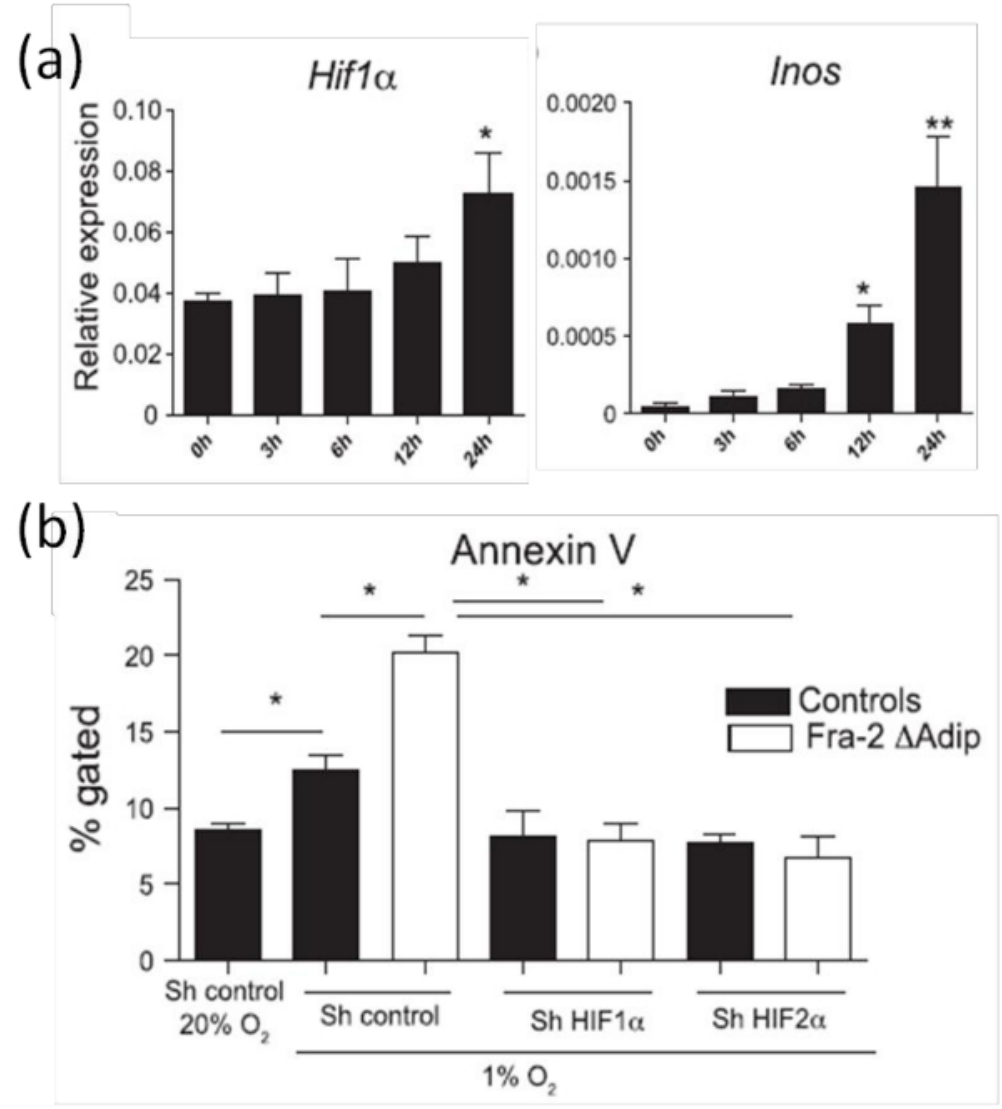

Figure 8: Increased HIF-1a expression and adipocyte apoptosis in primary adipocytes induced by hypoxia. (a) Real-time PCR analysis of HIF-1 $\alpha$ and HIFs target Inos mRNA levels in primary adipocytes placed in hypoxic chambers analyzed at the indicated time points. (b) Quantification of apoptosis by Annexin V FACS staining in primary adipocytes isolated from Fra- ${ }^{\mathrm{fl} / \mathrm{fl} / \mathrm{F}}$ Fabp4-CreERT mice or wild-type controls transfected with sh control or sh plasmid against HIF-1 $\alpha$ or HIF-2 $\alpha$ and placed under hypoxia $\left(1 \% \mathrm{O}_{2}\right)$ for 24 hr. This figure has been modified from Luther et al. ${ }^{9}$. Data are shown as mean values \pm S.D. Statistical analysis was performed using Student's $t$-test. ${ }^{*} P<0.05$ and ${ }^{* \star} P<0.01$ were accepted as significant. Please click here to view a larger version of this figure.

\section{Discussion}

Adipocytes are characterized phenotypically by their size, numbers and area, revealing adipocyte hyperplasia and hypertrophy, induced by excessive energy storage due to over-nutrition ${ }^{5}$. These events leading to fatty acid dysregulation and subsequent metabolic syndromes are also states of increased fat mass with preserved metabolisms, which is also referred to as "healthy" fat expansion. For example, Kusminski et al. ${ }^{21}$ showed that mice with massive fat expansion remain metabolically healthy, suggesting that fat expansion is not necessarily linked to metabolic syndromes and needs to be carefully determined to evaluate the characteristics of the adipocytes. The adipose tissue (AT) plays a pivotal role in the regulation of body metabolism. AT is the biggest endocrine organ that could influence dyslipidemia, atherosclerosis, hyperinsulinemia and hyperglycemia ${ }^{3}$. Evaluating AT homeostasis and the molecular mechanisms regulating it could allow a better understanding of metabolic system disorders. Therefore, unravelling the mechanisms regulating adipocyte differentiation, adipocyte size and fat pad mass would help to develop new therapeutic treatment for obesity disorders. Using in vivo and in vitro methods, it is possible to determine the role of food and gene expression impacts on adipocyte differentiation and activity. To determine the AT homeostasis, determining the balance between adipocyte differentiation, proliferation and apoptosis as suggested by our protocol is as important as analyzing the glucose and insulin metabolic response d22-24

Expression profiling analyses of genes involved in adipogenesis, lipogenesis, lipolysis, fatty acid uptake, hypoxia, apoptosis and proliferation in primary adipocytes and visceral AT is a high throughput method for obtaining an overview on adipocyte homeostasis and their possible dysfunction. Interesting candidates should be further analyzed at the protein level by western blot or immunohistological staining. To obtain optimal results through real-time PCR system using unsymmetrical cyanine dyes, the concentrations of cDNA ranging from 1 to $10 \mathrm{ng}$ and the optimal primer concentrations ranging from 50 to $900 \mathrm{nM}$ should be tested to minimize nonspecific amplification. The critical components are the primers; for each run, the melting curves need to be strictly controlled to ensure the specificity and to exclude the formation of primer dimers. Therefore, using a negative control with $\mathrm{H}_{2} \mathrm{O}$ instead of cDNA is recommended. Furthermore, commercial available unsymmetrical cyanine dyes are provided as master mixes that contain a passive reference dye (such as ROX) to provide an internal reference signal. The cDNA signal is normalized during data analysis to the ROX signals to correct well-to-well signal fluctuations. Another point to be considered in order to establish a good qPCR system is the choice of the housekeeping gene. For each condition, several housekeeping genes are used, e.g., HPRT, $\beta$-actin, GAPDH, $\beta-2-M G$ or HSP90. 
HIF proteins stabilized by hypoxic conditions are master regulators determining not only adipocytes survival, but also metabolic changes, such as glucose, insulin tolerance and lipid metabolism ${ }^{11,25,26}$. To ascertain hypoxic areas in the fat pad, HIF-1 $\alpha$ is determined in AT sections by immunohistochemistry. Since HIF proteins are rapidly degraded within 5 to 10 min under normoxic conditions, the procedure and the fixation of the fat pad for the histological analysis should be tightly controlled to avoid latency time. Therefore, to ensure hypoxia not only through HIF staining, pimonidazole is used to determine hypoxic areas in the AT. Pimonidazole is able to distribute into tissues, as it was already shown in bones ${ }^{27}$, and effectively mark hypoxic areas by binding to thiol-containing proteins specifically in hypoxic cells, which is further detected in histological sections by specific antibody binding ${ }^{28}$. However, other markers and methods can be used to analyze the hypoxia pathway. For example, the involvement of the prolyl hydroxylase (PHD) enzyme, which induce hydroxylation of proline residues under normoxia, as well as the von Hippel-Lindau (VHL) protein, which recognize hydroxylated prolines and induce the poly-ubiquitination to mediate proteasomal HIF degradation, need to be analyzed for a full overview of the pathway ${ }^{29,30}$. Moreover, ubiquitous detection of HIFs would also determine the protein stability and degradation that can be alter ${ }^{31,32}$.

Furthermore, proliferation by Ki67 and apoptosis by TUNEL staining are determined in vivo through staining of AT histological sections. Quantification of proliferation by Ki67 and apoptosis by TUNEL or Annexin V staining through flow cytometry analysis is also carried out ${ }^{33}$ Proliferation could of course be measured by other techniques such as the analyses of the adipocyte cell cycle, which is not addressed by the measurement of Ki67 positive cells. Moreover, apoptosis study by TUNEL can be completed by FACS analyses of Annexin V and TOP-PR-3 which will determine the levels of necrosis versus the apoptosis cell death process. Apoptosis is a fundamental process for the program of cell death, which is important for AT homeostasis. Indeed, dysregulation of adipocyte apoptosis has been implicated previously in processes contributing to obesity and lipodystrophy ${ }^{34}$. Moreover, in 2011 , Keuper et al. linked adipose tissue inflammation to adipocyte apoptosis. They showed that macrophages induced apoptosis in preadipocytes and adipocytes, which in turn attract macrophages. The recruitment of macrophages accelerates inflammation, which contributes to metabolic syndromes such as glucose and insulin tolerance ${ }^{35}$. However, adipocyte apoptosis is still a poorly studied phenomenon, despite the hypothesis that induced adipocyte apoptosis could lead to decreased weight.

The present protocol uses immunohistochemical approaches to study different phenomenon such as proliferation, apoptosis and hypoxia in vivo. Therefore, the tissue was fixed with $4 \%$ formaldehyde, which is a critical step. An extended tissue fixation time leads to change of the epitopes, which become non-accessible for the antibody. In contrast, a short fixation time increases the sensitivity of epitopes to reagents. The recommended optimal time of fixation is $24 \mathrm{hr}$. Moreover, the thickness of the sections also influences the antibodies binding to their epitopes; optimal thickness is between 2 and $5 \mu \mathrm{m}$. Sections thicker than $5 \mu \mathrm{m}$ will give false positive results due to increased binding sites. In contrast, sections thinner than $2 \mu \mathrm{m}$ contain less binding sites and positive areas are not well defined. Further critical factors are the antibody itself, incubation time, concentration and even temperature, which influence the quality of the specific binding to the epitopes. Therefore, validating antibody concentration and incubation time is necessary for each condition.

To complete the study, we provide an in vitro adipocyte differentiation protocol, which could be extended by different treatments, stimulation or co-cultures. By using in vitro adipocyte cultures, it is feasible to determine defects in adipocyte differentiation and functions. To obtain reliable results, as for all primary cells, the healthy behavior and appearance of the ADSCs and adipocytes is quite important. The granularity, cytoplasmic vacuolations and/or detachment are signs of deterioration, indicating inadequate medium, microbial contamination or senescence of the primary cells. This protocol is using isolated adipocytes from the fat pad tissue, whereas it is as well possible to use mesenchymal stem cell isolated from bone marrow as described by other protocols ${ }^{36}$. The latest includes stromal progenitor cells, which might reflect additional differentiation problems occurring at the very early step of adipocyte differentiation, this might be missed in our current protocol. Moreover, ADSCs can be expanded rapidly (more than 10 times within one week), and long-term cultured ADSCs after some passages still retain their mesenchymal pluripotency ${ }^{37,38}$. Another advantage using ADSCs is that one can easily switch to human, since ADSCs can be harvested from patients by liposuction which is a simple and minimally invasive method.

As AT influences several other organs in an endocrine manner, the protocol should be extended to adipokines. Adipokines, such as leptin, adiponectin, tumor necrosis factor- $\alpha$ (TNF) and resistin, secreted by adipocytes are known to affect metabolic diseases by controlling fat metabolism, energy homeostasis and insulin sensitivity ${ }^{39}$. Therefore, serum and adipocyte secretome analyses should be performed. In the case of AT dysfunction, adipokines and pro-inflammatory cytokines, such as IL-6, can lead to dysregulation of organs such as the liver and pancreas, and of muscle function ${ }^{4}$. In order to exclude systemic organ dysfunction, animal models or cell cultures could be tested for their response to glucose stimulation and uptake.

Here we provide a protocol for analyzing the basic state of the AT and adipocytes in vivo and in vitro to reveal molecular mechanisms of adipocyte homeostasis and functionality.

\section{Disclosures}

The authors have nothing to disclose.

\section{Acknowledgements}

The authors would like to kindly thank Dr. J. Luther and K. Ubieta for preparing the data and Dr. B. Grötsch for proofreading the manuscript. This work was supported by the Deutsche Forschungsgemeinschaft (BO3811/1-1-Emmy Noether).

\section{References}

1. WHO. Obesity and Overweight. Fact Sheet ${ }^{\circ} 113$. Jan (2014)

2. Gong, Z., \& Muzumdar, R. H. Pancreatic function, type 2 diabetes, and metabolism in aging. Int J Endocrinol. 2012, 320482 (2012).

3. Deng, Y., \& Scherer, P. E. Adipokines as novel biomarkers and regulators of the metabolic syndrome. Ann N Y Acad Sci. 1212, E1-E19 (2010). 
4. Rezaee, F., Dashty, M. Role of Adipose Tissue in Metabolic System Disorders Adipose Tissue is the Initiator of Metabolic Diseases. $J$ Diabetes Metab. S13, 008 (2013).

5. Rutkowski, J. M., Stern, J. H., \& Scherer, P. E. The cell biology of fat expansion. J Cell Biol. 208, 501-512 (2015).

6. Ma, X., Lee, P., Chisholm, D. J., \& James, D. E. Control of adipocyte differentiation in different fat depots; implications for pathophysiology or therapy. Front Endocrinol (Lausanne). 6, 1 (2015).

7. Farmer, S. R. Transcriptional control of adipocyte formation. Cell Metab. 4, 263-273 (2006).

8. Luther, J. et al. Elevated Fra-1 expression causes severe lipodystrophy. J Cell Sci. 124, 1465-1476 (2011).

9. Luther, J. et al. Fra-2/AP-1 controls adipocyte differentiation and survival by regulating PPARgamma and hypoxia. Cell Death Differ. (2014).

10. Semenza, G. L. Regulation of mammalian O2 homeostasis by hypoxia-inducible factor 1. Annu Rev Cell Dev Biol. 15, 551-578 (1999).

11. Kim, W., \& Kaelin, W. G., Jr. The von Hippel-Lindau tumor suppressor protein: new insights into oxygen sensing and cancer. Curr Opin Genet Dev. 13, 55-60 (2003).

12. Aragones, J., Fraisl, P., Baes, M., \& Carmeliet, P. Oxygen sensors at the crossroad of metabolism. Cell Metab. 9, 11-22 (2009).

13. Sun, K., Halberg, N., Khan, M., Magalang, U. J., \& Scherer, P. E. Selective inhibition of hypoxia-inducible factor 1alpha ameliorates adipose tissue dysfunction. Mol Cell Biol. 33, 904-917 (2013).

14. Imai, T., Jiang, M., Chambon, P., \& Metzger, D. Impaired adipogenesis and lipolysis in the mouse upon selective ablation of the retinoid $\mathrm{X}$ receptor alpha mediated by a tamoxifen-inducible chimeric Cre recombinase (Cre-ERT2) in adipocytes. Proc Natl Acad Sci U S A. 98, 224-228 (2001).

15. Clegg, D. J., Brown, L. M., Woods, S. C., \& Benoit, S. C. Gonadal hormones determine sensitivity to central leptin and insulin. Diabetes. 55, 978-987 (2006).

16. Haluzik, M. et al. Genetic background (C57BL/6J versus FVB/N) strongly influences the severity of diabetes and insulin resistance in ob/ob mice. Endocrinology 145, 3258-3264 (2004).

17. Chomczynski, P., \& Sacchi, N. Single-step method of RNA isolation by acid guanidinium thiocyanate-phenol-chloroform extraction. Analytical biochemistry. 162, 156-159 (1987).

18. Protocolsonline. Paraffin Processing of Tissue. <http://protocolsonline.com/histology/sample-preparation/paraffin-processing-of-tissue/> (2012).

19. Schneider, C. A., Rasband, W. S., \& Eliceiri, K. W. NIH Image to ImageJ: 25 years of image analysis. Nat Methods. 9, $671-675$ (2012).

20. Planat-Benard, V. et al. Plasticity of human adipose lineage cells toward endothelial cells: physiological and therapeutic perspectives. Circulation. 109, 656-663 (2004).

21. Kusminski, C. M. et al. MitoNEET-driven alterations in adipocyte mitochondrial activity reveal a crucial adaptive process that preserves insulin sensitivity in obesity. Nat Med. 18, 1539-1549 (2012).

22. Trajcevski, K. E. et al. Enhanced lipid oxidation and maintenance of muscle insulin sensitivity despite glucose intolerance in a diet-induced obesity mouse model. PLoS One. 8, e71747 (2013).

23. Montgomery, M. K. et al. Mouse strain-dependent variation in obesity and glucose homeostasis in response to high-fat feeding. Diabetologia. 56, 1129-1139 (2013)

24. de Queiroz, K. B. et al. Molecular mechanism driving retroperitoneal adipocyte hypertrophy and hyperplasia in response to a high-sugar diet. Mol Nutr Food Res. 58, 2331-2341 (2014).

25. Ye, J. Emerging role of adipose tissue hypoxia in obesity and insulin resistance. Int J Obes (Lond). 33, 54-66 (2009).

26. Xiong, Y. et al. The local corticotropin-releasing hormone receptor 2 signalling pathway partly mediates hypoxia-induced increases in lipolysis via the cAMP-protein kinase A signalling pathway in white adipose tissue. Mol Cell Endocrinol. 392, 106-114 (2014).

27. Bozec, A. et al. Osteoclast size is controlled by Fra-2 through LIF/LIF-receptor signalling and hypoxia. Nature. 454, 221-225 (2008).

28. Varia, M. A. et al. Pimonidazole: a novel hypoxia marker for complementary study of tumor hypoxia and cell proliferation in cervical carcinoma. Gynecol Oncol. 71, 270-277 (1998).

29. Park, M. H., Choi, K. Y., Jung, Y., \& Min do, S. Phospholipase D1 protein coordinates dynamic assembly of HIF-1alpha-PHD-VHL to regulate HIF-1alpha stability. Oncotarget. 5, 11857-11872 (2014).

30. Tennant, D. A. et al. Reactivating HIF prolyl hydroxylases under hypoxia results in metabolic catastrophe and cell death. Oncogene. 28, 4009-4021 (2009).

31. Kim, J., So, D., Shin, H. W., Chun, Y. S., \& Park, J. W. HIF-1alpha Upregulation due to Depletion of the Free Ubiquitin Pool. Journal of Korean medical science. 30, 1388-1395 (2015).

32. Amelio, I. et al. TAp73 opposes tumor angiogenesis by promoting hypoxia-inducible factor 1alpha degradation. Proceedings of the National Academy of Sciences of the United States of America. 112, 226-231 (2015).

33. Suga, H. et al. Adipose tissue remodeling under ischemia: death of adipocytes and activation of stem/progenitor cells. Plast Reconstr Surg. 126, 1911-1923 (2010).

34. Moreno-Indias, I., \& Tinahones, F. J. Impaired adipose tissue expandability and lipogenic capacities as ones of the main causes of metabolic disorders. J Diabetes Res. 2015, 970375 (2015).

35. Keuper, M. et al. An inflammatory micro-environment promotes human adipocyte apoptosis. Mol Cell Endocrinol. 339, 105-113 (2011).

36. Sera, Y. et al. Hematopoietic stem cell origin of adipocytes. Experimental hematology 37, 1108-1120, (2009).

37. Zuk, P. A. et al. Multilineage cells from human adipose tissue: implications for cell-based therapies. Tissue engineering 7, 211-228 (2001).

38. Zuk, P. A. et al. Human adipose tissue is a source of multipotent stem cells. Molecular biology of the cell 13, $4279-4295$ (2002).

39. Scherer, P. E. Adipose tissue: from lipid storage compartment to endocrine organ. Diabetes. 55, 1537-1545 (2006). 